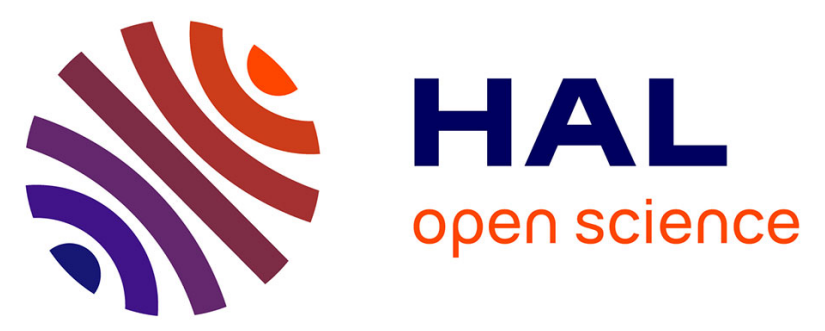

\title{
Theoretical and experimental study of the reaction between ammonium nitrate and sodium salts
} Stefania Cagnina, Patricia Rotureau, Shanti Singh, Richard Turcotte, Guillaume Fayet, Carlo Adamo

\section{- To cite this version:}

Stefania Cagnina, Patricia Rotureau, Shanti Singh, Richard Turcotte, Guillaume Fayet, et al.. Theoretical and experimental study of the reaction between ammonium nitrate and sodium salts. Industrial and engineering chemistry research, 2016, 55 (47), pp.12183-12190. 10.1021/acs.iecr.6b02834 . ineris01863107

HAL Id: ineris-01863107

https://hal-ineris.archives-ouvertes.fr/ineris-01863107

Submitted on 28 Aug 2018

HAL is a multi-disciplinary open access archive for the deposit and dissemination of scientific research documents, whether they are published or not. The documents may come from teaching and research institutions in France or abroad, or from public or private research centers.
L'archive ouverte pluridisciplinaire HAL, est destinée au dépôt et à la diffusion de documents scientifiques de niveau recherche, publiés ou non, émanant des établissements d'enseignement et de recherche français ou étrangers, des laboratoires publics ou privés. 


\title{
A theoretical and experimental study of the reaction between ammonium nitrate and sodium salts
}

\author{
Stefania Cagnina ${ }^{\mathrm{a}, \mathrm{b}}$, Patricia Rotureau ${ }^{\mathrm{b}, *}$, Shanti Singh ${ }^{\mathrm{c}}$, Richard Turcotte ${ }^{\mathrm{c}}$, Guillaume Fayet ${ }^{\mathrm{b}}$, \\ and Carlo Adamo ${ }^{\mathrm{a}, \mathrm{d}}$
}

${ }^{a}$ Institut de Recherche Chimie Paris, PSL University CNRS Chimie Paris-Tech, 11 rue P. et M. Curie, F-75005 Paris, France; ' Institut National de l'Environnement Industriel et des Risques (INERIS), Parc Technologique Alata, BP2, 60550 Verneuil-en-Halatte, France; ${ }^{c}$ Canadian Explosives Research Laboratory Natural Resources Canada, 1 Haanel Drive, Bells Corners Complex-Building 12, Ottawa, ON K1A 1M1, Canada ; Institut Universitaire de France, 103 Boulevard Saint Michel, 75005 Paris, France

\begin{abstract}
Hazards posed by chemical incompatibility, especially in a large-scale industrial environment, warrant a deeper understanding of the mechanisms of the reactions involved in these phenomena. In this study, reactions between ammonium nitrate and two sodium salts, namely sodium nitrate and sodium nitrite, have been studied by ab initio calculations (with Density Functional Theory, DFT) and experimental calorimetric methods (with Differential Scanning Calorimetry, DSC and Heat Flux Calorimetry, HFC). The agreement between theoretical and experimental results allows an understanding of the thermal decomposition behaviours of the two sodium salts when exposed to ammonium nitrate. Moreover, this study highlighted the critical role of the water that appears to promote the incompatibility between ammonium nitrate and sodium nitrite.
\end{abstract}

a) Chimie ParisTech; b) INERIS; c) CERL; d) IUF

*corresponding author: patricia.rotureau@ineris.fr 


\section{Introduction}

Million ton quantities of ammonium nitrate (AN) are used in the manufacture of inorganic fertilizers and industrial mining explosives ${ }^{1}$, and often specialty formulations are produced containing new chemicals which are more cost effective, or contain additives to enhance AN usefulness. Plants which manufacture AN-based products necessarily stock many other chemicals onsite and, to ensure safe operations, a priori knowledge of AN incompatibilities is necessary. Indeed, AN is a strong oxidizer with known incompatibilities towards many substances, such as metals, sulfur, sulfides, halides, and organics. ${ }^{2-9}$ Such incompatibilities are known to reduce the runaway temperatures and sometimes increase the reaction enthalpies. ${ }^{10-12}$ This process can lead to tragic consequences if AN contamination by an onsite chemical could happen during manufacture, as may have occurred in several accidents. ${ }^{13-}$ ${ }^{15}$ Indeed, such an incompatibility between AN and the sodium salt of dichloroisocyanurate (SDIC) has been demonstrated experimentally by calorimetric analysis ${ }^{16-17}$ and more recently by theoretical simulations. ${ }^{19-21}$

The focus of the present work is to study the incompatibility of AN towards two process chemicals, pure sodium nitrite $\left(\mathrm{NaNO}_{2}\right)$ and sodium nitrate $\left(\mathrm{NaNO}_{3}\right)$, using a combined experimental and theoretical approach. These chemicals are used in the manufacture of water-in-oil ammonium nitrate emulsion (ANE) explosives ${ }^{22}$ and large quantities of these sodium salts may be present in the industrial environment. In particular, $\mathrm{NaNO}_{2}$ represents a very inexpensive source to produce nitrogen gas bubbles via a nitrosation reaction when mixed into a solution of ammonium nitrate. In an ANE explosive, the presence of such evenly dispersed small voids enhances the ignitability and the ability of the explosive to undergo steady detonation. The real danger of powdered $\mathrm{NaNO}_{2}$ coming into contact with AN emulsion explosive at a manufacturing site has been reported anecdotally. ${ }^{23-25}$ Sodium nitrate is used as a complementary oxidizer which, in aqueous solution with ammonium nitrate, aids to reduce the process temperature required to emulsify the oxidizer solution. It also enhances the final properties of the ANE towards detonation performance. ${ }^{22}$ In addition, it is a very cheap commodity in some parts of the world, helping in reducing production costs. No industrial accident has been reported in the literature concerning a chemical incompatibility between AN and sodium nitrate.

The thermal stability of energetic materials such as ANE is usually estimated by the external temperature required to induce an exothermic decomposition. From an experimental point of view, the thermal instability of a mixture of AN with additive(s) would be characterized by a 
lower decomposition temperature, when tested using calorimetric methods and the same configuration as pure AN. Differential Scanning Calorimetry (DSC) and Heat Flux Calorimetry (HFC) using upwards from 1 to 100 milligram sample sizes are capable of indicating such thermal instabilities ${ }^{2,26}$ and were chosen as the experimental methods in the present work. But these experiments do not give details about the molecular reactions involved in the decomposition process.

Recently, in an attempt to better understand reaction pathways leading to instabilities, theoretical methods have been developed..$^{20,27-28}$ In particular, a complete Density Functional Theory (DFT) study performed on pure AN, pure SDIC and on the system of AN-SDIC identified all the structures of the intermediates and products involved in the decomposition reactions and clarified the incompatibility between these substances. It evidenced the catalytic role of water in promoting the decomposition of AN when in contact with SDIC through a significant decrease of the activation energy of the rate-determining step of the reaction mechanism. In a similar way, this work aims to clarify the potential incompatibility of AN with sodium salts $\mathrm{NaNO}_{2}$ and $\mathrm{NaNO}_{3}$ using a combined experimental and theoretical approach based on calorimetric analysis and the DFT approaches. Our previous detailed work on the chemical incompatibility between $\mathrm{AN}$ and $\mathrm{SDIC}^{20}$ suggested that through the analysis of the rate determining step, the reaction between ammonia and nitric acid in the presence of sodium salts already provides valuable information on the presence (or absence) of a chemical incompatibility. Following this indication, the present DFT work will be focused only on the evaluation of different chemical factors on the energetics of the rate-determining step of the reaction mechanism between AN and sodium salts in order to identify the presence of a chemical incompatibility.

\section{Materials and methods}

\subsection{Experimental details}

Chemicals:

AN (ACS reagent grade, 95\% min. purity, Alfa Aesar) was dried overnight at $70^{\circ} \mathrm{C}$ in an explosion-proof oven to promote bulk water loss and further minimize dissociation of the salt to $\mathrm{HNO}_{3}$ and $\mathrm{NH}_{3}$. Immediately after drying, the free-flowing white crystals were stored with desiccant under a positive pressure of argon since AN is hygroscopic. All calorimetric tests were performed using the same batch of dried AN. Sodium nitrate $(\geq 99 \%$ purity, Sigma Aldrich) was dried at $105^{\circ} \mathrm{C}$ and stored under argon before use. Sodium nitrite (> $99 \%$ purity, 
J.T. Baker) was used as received. The loss of crystal-bound or otherwise surface-adsorbed water molecules using high temperatures was not attempted to avoid degradation of the pure sample.

\section{Calorimetry:}

A TA Instrument 2910 DSC with associated analysis software was used for the thermal study of $\mathrm{AN}, \mathrm{NaNO}_{2}, \mathrm{NaNO}_{3}$ and binary mixtures thereof. This calorimeter works on the principle of supplying a linear heating rate to a furnace containing a reference and sample holder, each equipped with appropriate temperature sensors. The differential behaviour of the sample is recorded as the heat flow into and out of the holders, and provides enthalpy data regarding endothermic or exothermic events. A Setaram C80 Calvet heat flux calorimeter was used for larger scale thermal stability testing of $\mathrm{AN}+\mathrm{NaNO}_{2}$. In this calorimeter the sample size is typically 100X larger than that used in DSC. A 3D arrangement of thermopiles surrounds the sample and allows very small temperature excursions to be detected when using a very slow ramp rate (i.e., $0.1{ }^{\circ} \mathrm{C} \mathrm{min}^{-1}$ ). These quasi-adiabatic conditions with the larger sample size enable self-heating effects to be detected if a reaction is sufficiently exothermic.

The DSC was calibrated for temperature and heat flow using standard methods. ${ }^{29-30}$ The samples were heated at $5{ }^{\circ} \mathrm{C} \mathrm{min}{ }^{-1}$ under an inert purge atmosphere of $50 \mathrm{~mL} \mathrm{~min}^{-1}$ of nitrogen gas, and encapsulated within hermetically sealed (cold welded) aluminum pans having an internal volume of approximately 30 microliters and pressure capability of $0.2 \mathrm{MPa}$ (2 atm). This volume permitted approximately one to five milligrams of the pure salt or the mixture to be tested; however, pressure from decomposition gases sometimes ruptured the aluminum weld. Since manipulation at milligram scale was required, the most reproducible method to obtain representative DSC thermograms involved directly adding the appropriate weight of components directly to the DSC pan. Only a few dried crystals of each salt were required so a 50/50 mass ratio was targeted for the mixtures, and final AN/salt mass ratios between 52/48 to 60/40 were attained. The samples were prepared dry under $<40 \%$ relative humidity conditions to minimize adsorbed moisture and, additionally, showed no drift when weighing on an ultra-microbalance capable of $\pm 0.00001 \mathrm{mg}$ resolution. When known amounts of water were required, a micro droplet of $18 \mathrm{M} \Omega$ distilled deionized water was first syringed into an empty pan and allowed to evaporate while on a microbalance until the appropriate weight was obtained, then the dried powders were quickly added and the pans were sealed. The AN/salt mixture was noted to be humid with mass $\%$ water between $~ 1-3 \%$ 
and the individual crystals still free flowing. A mixture containing excess water was noted at $\sim 10$ mass \% water, in which case all the crystals were lightly agglomerated into a single mass. Mixtures were tested in at least duplicate runs.

The heat flux calorimeter was factory calibrated for heat flow using the joule effect, and verified using metal standards for enthalpy and temperature. ${ }^{29-30}$ A quartz liner was used to contain a $150 \mathrm{mg}$ sample of dried $\mathrm{AN}$ and $\mathrm{NaNO}_{2}$ powder in a 50/50 mass ratio. The quartz liner was loaded into a $10 \mathrm{~mL}$ stainless steel vessel equipped with a pressure transducer, flushed with dry air. Pressure, temperature and heat flow were recorded as the vessel was heated at $0.1^{\circ} \mathrm{C} \mathrm{min}^{-1}$ from room temperature to $300^{\circ} \mathrm{C}$.

\subsection{Computational details}

All the calculations were performed using the Gaussian 09 software package. ${ }^{31}$ Stationary point optimizations were performed using the M06-2X functional ${ }^{32}$ and $6-311+G(2 d, 2 p)$ basis set. ${ }^{33-34}$ This level of theory has been proven to provide the most accurate energetics data, among a large series of functionals and basis sets, for the decomposition of pure ammonium nitrate. ${ }^{27}$ The nature of the stationary points was checked by vibrational analysis and minima (no imaginary frequency) and transition states (one imaginary frequency) were so identified. For transition-state structures (TS), when the inspection of the normal mode related to the imaginary frequency was not sufficient to confidently establish its connection with the initial and final stable species, Intrinsic Reaction Coordinate (IRC) calculations were performed. ${ }^{35}$ Total energies, enthalpies and Gibbs free energies were computed for all the identified intermediates and products at standard conditions $\left(25^{\circ} \mathrm{C}, 1 \mathrm{~atm}\right)$.

All radicals were calculated within a spin-unrestricted formalism and spin contamination, monitored by the expectation value of $S^{2}$, was found to be negligible. Finally, the catalytic and/or solvation role of water is taken into account by the addition of an explicit water molecule and/or an implicit solvent model. In the last case, the integral equation formalism (IEF) extension of the polarizable continuum model (PCM) ${ }^{36}$ was also used.

\section{Results and discussion}

\subsection{Calorimetry results}

Calorimetry test results of the pure salts and the effect of the addition of $\mathrm{NaNO}_{2}$ or $\mathrm{NaNO}_{3}$ to AN are presented in Figure 1. Strong melting endotherms of pure $\mathrm{NaNO}_{2}$ and $\mathrm{NaNO}_{3}$ were detected at $280^{\circ} \mathrm{C}$ and $308^{\circ} \mathrm{C}$ respectively, consistent with the supplier data. ${ }^{37}$ Pure AN showed the expected endotherms due to solid-solid phase transitions at $55^{\circ} \mathrm{C}, 125^{\circ} \mathrm{C}$ and 
melting at $169^{\circ} \mathrm{C}$, followed by exothermic decomposition starting from $220^{\circ} \mathrm{C} .{ }^{38}$ In this particular sample, the uneven shape of the AN exotherm indicated that pressure due to the generation of gaseous decomposition products breached the aluminum pan cold weld.

The mixtures showed varying thermal behaviours depending on the amount of water present. In the case of the $\mathrm{AN}+\mathrm{NaNO}_{2}$ mixtures (Figure 1a), only the first solid-solid AN phase transition at $55^{\circ} \mathrm{C}$ is detected. This small transition is immediately followed by a significant exotherm in both the dry and wetted samples. Although this low temperature exotherm consumes most of the AN and sodium nitrite, residual unreacted salt may still be present. This is indicated by the appearance of a second (sharp) exotherm in the dry system, approaching the region where pure AN is shown to decompose. So, an incompatibility is highlighted between $\mathrm{AN}$ and $\mathrm{NaNO}_{2}$.

In the case of $\mathrm{AN}+\mathrm{NaNO}_{3}$ mixtures (Figure 1b), the first two solid-solid $\mathrm{AN}$ phase transitions at $55^{\circ} \mathrm{C}$ and $125^{\circ} \mathrm{C}$ were still detected separately in the dry and wetted samples since the amount of added water was not sufficient to dissolve AN. Close examination of the dried $\mathrm{AN}+\mathrm{NaNO}_{3}$ sample showed an onset to decomposition starting at $\sim 220^{\circ} \mathrm{C}$ likely followed by catastrophic rupture of the aluminum container (visible on the pan weld after the completed experiment). The addition of water to the mixture not only reduced the detectability of the AN endothermic transitions but also greatly diluted the AN decomposition enthalpy as indicated by the very weak and broad exotherm. Additional exotherms were not detected indicating no thermal incompatibility with $\mathrm{NaNO}_{3}$.

Table 1 lists the enthalpies of decomposition for the first exotherm in both systems; $\mathrm{AN}+\mathrm{NaNO}_{2}$ is significantly more energetic and less thermally stable than pure AN or $\mathrm{AN}+\mathrm{NaNO}_{3}$. The onset temperature to decomposition is consistently low for $\mathrm{AN}+\mathrm{NaNO}$, and of sufficient energy output, to warrant isothermal tests near room temperature. As such, the quasi-adiabatic calorimetry test (HFC) shown in Figure 1c is a slow ramp from room temperature and resulted in the largest enthalpy of all tests. A decomposition reaction was recorded after five hours at which time the sample had only reached $54^{\circ} \mathrm{C}$. These results strongly suggest that the presence of $\mathrm{NaNO}_{2}$ in a manufacturing environment, for example in the form of a layer of dust, would need to be safely isolated from coming into contact with solid AN.

\subsection{Theoretical results}

\subsubsection{Reminder of the decomposition of pure AN and of the mixture AN - SDIC}


The decomposition mechanism of pure ammonium nitrate in the gas phase was studied in our first study concerning ammonium nitrate ${ }^{27}$ and the main reaction channels were identified. Briefly, the first step of the decomposition of $\mathrm{AN}$ (described by reaction 1) is a slightly exothermic dissociation of the molecule $\left(\Delta \mathrm{G}=4.9 \mathrm{kcal} \mathrm{mol}^{-1}\right)$ into ammonia and nitric acid.

$$
\text { 1) } \mathrm{NH}_{4} \mathrm{NO}_{3} \rightarrow \mathrm{HNO}_{3}+\mathrm{NH}_{3}
$$

The nitric acid then undergoes a homolytic breaking of the $\mathrm{N}-\mathrm{O}$ bond at higher energy $(\Delta \mathrm{G}=$ $40.2 \mathrm{kcal} \mathrm{mol}^{-1}$ ), giving the formation of nitrogen dioxide and hydroxyl radicals (see reaction 2).

$$
\text { 2) } \mathrm{HNO}_{3} \rightarrow{ }^{\bullet} \mathrm{NO}_{2}+\mathrm{OH}^{\bullet}
$$

This is the rate determining step of the decomposition of pure AN. Then, the hydroxyl radical reacts with the ammonia molecule forming the amidogen radical $\left(\mathrm{NH}_{2}{ }^{\bullet}\right)$ and water, and starting from this step different radical couplings can occur between amidogen and nitrogen dioxide, producing all the products characterized experimentally $\left(\mathrm{N}_{2}, \mathrm{H}_{2} \mathrm{O}, \mathrm{O}_{2}, \mathrm{HNO}\right)$.

The incompatibility between AN and SDIC was analyzed in our second work ${ }^{20}$ and the identified mechanism involved the reaction between ammonia (formed by AN decomposition) and the sodium salt of dichloroisocyanuric acid. In this case, the rate determining step is a concerted transfer of the chlorine atom of SDIC to the nitrogen atom of ammonia and a hydrogen atom of $\mathrm{NH}_{3}$ to the carbon atom of the chlorate sodium salt. This step is high in energy in the gas phase $\left(58.0 \mathrm{kcal} \mathrm{mol}^{-1}\right)$ but a water molecule catalyzes the reaction, inducing a significant decrease of the energy barrier (down to $32.1 \mathrm{kcal} \mathrm{mol}^{-1}$ ), so that the reaction between $\mathrm{AN}$ and SDIC becomes competitive with the decomposition of the pure AN, according to reaction 3.

$$
\text { 3) } \mathrm{SDIC}+\mathrm{NH}_{3}+\mathrm{H}_{2} \mathrm{O} \rightarrow \mathrm{SMIC}+\mathrm{NH}_{2} \mathrm{Cl}+\mathrm{H}_{2} \mathrm{O}
$$

The pivotal role of water (even at trace levels) in the chemical incompatibility between the two substances, also indicated in DSC experiments published in earlier literature ${ }^{16,17}$, is due to its role as a bridge to allow a hydrogen transfer between $\mathrm{NH}_{3}$ and SDIC.

\subsection{2. $A N-\mathrm{NaNO}_{2}$ reaction}




\section{Decomposition of pure $\mathrm{NaNO}_{2}$}

According to Sutton and Addison ${ }^{39}, \mathrm{NaNO}_{2}$ may be considered as a stable substance since the decomposition takes place much above the melting point at high temperature (between $400^{\circ} \mathrm{C}$ and $600^{\circ} \mathrm{C}$ ). Here, in the commonly accepted decomposition mechanism ${ }^{39}$, a metal nitrite decomposes to form nitrogen and the corresponding metal oxide.

In agreement with published literature ${ }^{39-40}$, it was found that the decomposition does not occur at standard conditions because the reaction requires a Gibbs free energy $(\Delta \mathrm{G})$ of 71.9 kcal mol ${ }^{-1}$ to form sodium monoxide $(\mathrm{NaO})$ and nitrogen monoxide (NO) according to reaction 4:

$$
\text { 4) } \quad \mathrm{NaNO}_{2} \rightarrow \mathrm{NaO}+\mathrm{NO}
$$

\section{Reaction mechanism of the mixture $\mathrm{AN}-\mathrm{NaNO}_{2}$}

Following the procedure defined to study the incompatibility between AN and SDIC ${ }^{20}$ once the decomposition of pure products is characterized, the attention is focused on the identification of the reaction mechanism of $\mathrm{AN}-\mathrm{NaNO}_{2}$ mixture, with a particular attention to the rate determining $\operatorname{step}^{20}$ : the direct reaction between the products of the first decomposition of $\mathrm{AN}\left(\mathrm{NH}_{3}\right.$ or $\left.\mathrm{HNO}_{3}\right)$ and the contaminant.

Since AN decomposes into nitric acid and ammonia, passing through a weakly endothermic step $\left(\Delta \mathrm{G}=4.9 \mathrm{kcal} \mathrm{mol}^{-1}\right)$, the reaction of sodium nitrite with both species has been considered:

$$
\begin{aligned}
& \text { 5) } \\
& \text { 6) } \mathrm{NaNO}_{2}+\mathrm{NH}_{3} \rightarrow \mathrm{NaH}+\mathrm{NH}_{2} \mathrm{NO}_{2} \\
& \mathrm{NaNO}_{2}+\mathrm{HNO}_{3} \rightarrow \mathrm{NaOH}+2 \mathrm{NO}_{2}
\end{aligned}
$$

Our calculations suggest that reaction 5), leading to the formation of $\mathrm{NaH}$ and a nitramide molecule $\left(\mathrm{NH}_{2} \mathrm{NO}_{2}\right)$, has a very high activation barrier $\left(\Delta \mathrm{G}^{\neq}=101.0 \mathrm{kcal} \mathrm{mol}^{-1}\right)$, whereas reaction 6), giving $\mathrm{NaOH}$ and two molecules of $\mathrm{NO}_{2}$, is characterized by a transition state (see Figure 2) with a relative Gibbs free energy of $44.1 \mathrm{kcal} \mathrm{mol}^{-1}$. The very high barrier of the first path makes it significantly less probable than the second, so that only the latter (reaction 6) will be further considered (see Table 2). Two major points should be retained from these results. The first one concerns the energy barrier which is higher than the decomposition of AN (49.0 vs $40.2 \mathrm{kcal} / \mathrm{mol}$ ), thus ruling out an incompatibility between the two species as shown by experimental results (see Figure 1). The second relevant point 
concerns the difference with respect to the AN-SDIC reaction. In the case of SDIC, the origin of the incompatibility is rationalized in terms of a reaction between ammonia and the contaminant, while in the case of sodium nitrite and ammonium nitrate, it is the nitric acid that plays a key role in the interaction with $\mathrm{NaNO}_{2}$. It should be also noted that the computed enthalpies for the transition state and the products are very close to each other $(47.4 \mathrm{kcal} / \mathrm{mol}$ vs $47.7 \mathrm{kcal} / \mathrm{mol}$ ) indicating a strong delocalization of the molecular configuration, stemming from the relevant contribution of the larger number of vibrational states to the enthalpy.

\section{i. Role of the water on $\mathrm{AN}-\mathrm{NaNO}_{2}$ reaction}

Sodium nitrite and AN are two extremely hygroscopic salts and in the experimental protocol samples were not subjected to complete drying. But water could have a strong influence on decomposition mechanisms, as demonstrated for the AN-SDIC incompatibility ${ }^{20}$. Therefore, water was introduced in the theoretical model to simulate the experimental conditions and to better understand the reaction mechanism between sodium nitrite and nitric acid. At first, the effect of a water molecule on the transition state was considered (see Figure 2), as done for the AN-SDIC mixture ${ }^{20}$. As shown in Figure 3, the presence of a water molecule causes a decrease in the activation barrier for the reaction of $7.4 \mathrm{kcal} \mathrm{mol}^{-1}$ which makes the reaction between $\mathrm{AN}$ and sodium nitrite $\left(\Delta \mathrm{G}^{\neq}=36.7 \mathrm{kcal} \mathrm{mol}^{-1}\right)$ competitive in comparison to the decomposition of the pure $\mathrm{AN}\left(\Delta \mathrm{G}=40.2 \mathrm{kcal} \mathrm{mol}^{-1}\right)$. This result, consistent with experimental data, evidenced the role of water on the incompatibility between the two substances. However, unlike the reaction between the AN and $\mathrm{SDIC}^{20}$, the water is not directly involved in the reaction but facilitates the reaction by promoting the formation of a complex network of non-covalent interactions between the atoms involved in the transition state.

In order to have a clearer idea of the role of water, solvent bulk effects were also added using the PCM approach on both the $\mathrm{AN}-\mathrm{NaNO}_{2}$ dimer, and the $\mathrm{AN}-\mathrm{NaNO}_{2}-\mathrm{H}_{2} \mathrm{O}$ trimer. In both cases, an increase of the activation energy barrier (8.5 and $9.9 \mathrm{kcal} \mathrm{mol}^{-1}$, respectively) is observed (see Table S1). This increase is directly related to the stabilization of charge separated complexes, where the positive charge localized on the $\mathrm{Na}$ atom increases, while the negative charge on the $\mathrm{NO}_{2}$ group (located on the opposite side of the $\mathrm{OH}$ moiety, see Figure 2) decreases (more negative). Indeed, using the polarizable continuum model, the geometry of the transition state is slightly different: the $\mathrm{NaOH}$ molecule tends to its ionic form $\left(\mathrm{Na}^{+}\right.$ and $\mathrm{OH}^{-}$) and $\mathrm{NO}_{2}$ groups tend to $\mathrm{NO}_{2}^{-}$ion (Figure 2). In contrast, in the presence of an 
explicit water molecule, this charge separation is less important and the tendency to form ionic species is actually less significant. Globally a direct relation between the increasing of the $\mathrm{Na}$ charge and the activation energy can be traced (see Figure 4). However, the clear discrepancy with respect to the experimental data indicate that, in this specific case, continuum solvent models (PCM) are not realistic and we believe that the simple system with an explicit water model is more representative.

\subsection{3. $\mathrm{AN}-\mathrm{NaNO}_{3}$ reaction}

\section{Decomposition of pure $\mathrm{NaNO}_{3}$}

After the study of sodium nitrite, interest was focused on sodium nitrate and its reaction mechanism with AN. Sodium nitrate is a crystalline compound, colourless, odourless which finds application in many fields, ranging from agriculture to explosives. ${ }^{41}$ It is used in the production of fertilizer for its low cost and its ability to increase the amount of nitrogen in the soil, but it is also used as a pesticide, as an antimicrobial agent in the food industry to ensure conservation, in the manufacture of fireworks and in the production of explosives ${ }^{42}$.

Sodium nitrate has a melting point near $308^{\circ} \mathrm{C}$. If heated to decomposition, it emits toxic gases (including nitrogen oxides), but the salt itself is non-detonable. ${ }^{43}$ Literature indicates that the decomposition of the sodium nitrate begins, slowly, at $600^{\circ} \mathrm{C}$ and accelerates from $756^{\circ} \mathrm{C}^{44}$

According to experiments conducted by Freeman in $1956^{44}$, the reaction is generally completed at $910^{\circ} \mathrm{C}$ and the weight loss curves obtained by thermogravimetry indicates the presence of only sodium oxide and nitrogen dioxide that excludes the occurrence of more than one reaction. However, data from another study performed by mass spectrometry ${ }^{45}$ pointed out that the first step of the decomposition of the sodium nitrate mainly involves the formation of sodium nitrite and oxygen and that the decomposition of sodium nitrite into sodium oxide only takes place in a second step.

Two different reactions, consistent with those proposed in literature, were taken into account. The first one (reaction 7) is a reaction that, starting from sodium nitrate, leads directly to the formation of sodium oxide and nitrogen dioxide (products experimentally identified by thermogravimetry) with a Gibbs free energy of $82.3 \mathrm{kcal} \mathrm{mol}^{-1}$ :

7) $\quad \mathrm{NaNO}_{3} \rightarrow \mathrm{NaO}+\mathrm{NO}_{2}$. 
The second one (reaction 8) is a reaction which provides the decomposition of the sodium nitrate into sodium nitrite and oxygen (products experimentally identified by mass spectrometry) with a Gibbs free energy of $132.6 \mathrm{kcal} \mathrm{mol}^{-1}$ :

$$
\text { 8) } \quad \mathrm{NaNO}_{3} \rightarrow \mathrm{NaNO}_{2}+1 / 2 \mathrm{O}_{2}
$$

The $\Delta \mathrm{G}$ obtained for both reactions confirm what the literature and calorimetric results (Figure 1b) suggest, namely that sodium nitrate does not decompose at room temperature. Moreover, it can be observed that among the two reactions, the one leading directly to sodium oxide and nitrogen dioxide is favoured (in terms of energy) compared to the other one.

\section{Reaction mechanism of the mixture $\mathrm{AN}_{-} \mathrm{NaNO}_{3}$}

After the study of decomposition of pure sodium nitrate, a decomposition mechanism between the sodium salt and AN has been considered. As for the sodium nitrite study, the decomposition of the mixture has not been the subject of a complete study of the reaction mechanism: only the rate determining steps of the direct reaction between the two products (reactions: $\mathrm{NH}_{3}+\mathrm{NaNO}_{3}$ and $\mathrm{HNO}_{3}+\mathrm{NaNO}_{3}$ ) were analyzed in detail:

9) $\mathrm{NaNO}_{3}+\mathrm{NH}_{3} \rightarrow \mathrm{NaOH}+\mathrm{NH}_{2} \mathrm{NO}_{2}$

$$
\mathrm{NaNO}_{3}+\mathrm{HNO}_{3} \rightarrow \mathrm{NaOH}+\mathrm{N}_{2} \mathrm{O}_{5}
$$

The first reaction (reaction 9)), leads to the formation of sodium hydroxide $(\mathrm{NaOH})$ and nitramide $\left(\mathrm{NH}_{2} \mathrm{NO}_{2}\right)$ with an activation Gibbs free-energy of $71.8 \mathrm{kcal} \mathrm{mol}^{-1}$. The second one, (reaction 10)), gives a sodium hydroxide and a dinitrogen pentoxide molecule $\left(\mathrm{N}_{2} \mathrm{O}_{5}\right)$ with an activation Gibbs free energy of $50.7 \mathrm{kcal} \mathrm{mol}^{-1}$.

As before, the reaction between nitric acid and sodium nitrate is favoured in comparison to the reaction between ammonia and sodium nitrate. For this reason, only the latter will be retained for the rest of the theoretical study, aiming to investigate the incompatibility experimentally observed (Figure $1 b$ ).

Comparing the energies obtained for the decomposition of pure $\mathrm{AN}\left(\Delta \mathrm{G}=40.2 \mathrm{kcal} \mathrm{mol}^{-1}\right)$ with the ones obtained for the reaction between $A N$ and sodium nitrate $\left(\Delta \mathrm{G}^{\neq}=50.7 \mathrm{kcal} \mathrm{mol}{ }^{-}\right.$ ${ }^{1}$ ), the study confirms the results shown by calorimetry (Figure 1b): no incompatibility exists between the two chemicals. In fact, the presence of the sodium nitrate does not cause a decrease in the activation energy barrier. 
The geometry of the transition state of reaction 10) shown in Figure 5 presents a similarity with the transition state of the reaction between sodium nitrite and nitric acid (Figure 2). From a qualitative point of view, by visualization of the normal vibration mode, it is possible to see that in both cases the atoms involved are $\mathrm{O}-\mathrm{N}-\mathrm{O}$, wherein the first oxygen comes from $\mathrm{NaOH}$, nitrogen comes from $\mathrm{NO}_{2}$ and the second oxygen comes from $\mathrm{NO}_{2}$ or $\mathrm{NO}_{3}$ (depending on the salt under study) and that the imaginary frequency of the two transition states has a similar value $\left(\omega_{\text {TS_NaNO3 }}=256 \mathrm{i} \mathrm{cm}^{-1}\right.$ and $\left.\omega_{\text {TS_NaNO2 }}=202 \mathrm{i} \mathrm{cm}^{-1}\right)$.

Considering the hygroscopic nature of $\mathrm{AN}$ and sodium nitrate and the catalytic effect that water exerts on the incompatibility reaction between AN and SDIC, and between AN and $\mathrm{NaNO}_{2}$, a study including water was also performed.

\section{ii. Role of the water on $\mathrm{AN}-\mathrm{NaNO}_{3}$ reaction}

In a first step, an explicit water molecule has been introduced in the geometry of the transition state $\left(\mathrm{TS}_{\mathrm{NaNO}+\mathrm{HNO} 3}\right)$, as shown in Figure 5. As in the case of sodium nitrite, water in the $\mathrm{TS}_{\mathrm{NaNO} 3+\mathrm{HNO} 3}$ does not intervene directly in the reaction, but forms a complex network of non-covalent interactions between atoms involved in the transition state. Although the weak interactions formed between atoms cause a decrease in the activation barrier of the reaction of $9 \mathrm{kcal} \mathrm{mol}^{-1}$, the energy associated with the barrier remains higher $\left(\Delta \mathrm{G}^{\neq}=41.7\right.$ $\left.\mathrm{kcal} \mathrm{mol}^{-1}\right)$ compared to the decomposition energy of pure AN $\left(\Delta \mathrm{G}=40.2 \mathrm{kcal} \mathrm{mol}^{-1}\right)$. So, even in a wet environment, no incompatibility can be evidenced.

The influence of using PCM on the $\mathrm{AN}-\mathrm{NaNO}_{3}$ dimer and the $\mathrm{AN}-\mathrm{NaNO}_{3}-\mathrm{H}_{2} \mathrm{O}$ trimer was also tested. Data obtained confirmed the trend already observed for sodium nitrite: in both cases, an increase of the activation energy of about $16 \mathrm{kcal} \mathrm{mol}^{-1}$ occurs (see Figure 6). As in the case of $\mathrm{NaNO}_{2}$, the behaviour of the energy towards the method used to model water can be explained by the charges formed on the atoms involved in the transition state. Indeed, PCM on $\mathrm{AN}-\mathrm{NaNO}_{3}$ dimer and $\mathrm{NaNO}_{3}-\mathrm{H}_{2} \mathrm{O}$ trimer involves a charge separation (Table S2) that entails small geometric changes in the transition state as shown in Figure 5. Again a direct relation between an increasing $\mathrm{Na}$ charge and the activation energy can be traced (see Figure 4).

Overall, similar to $\mathrm{NaNO}_{2}$, data obtained show that in the reaction between sodium nitrate and $\mathrm{AN}$, only the explicit water molecule acts towards an energy barrier decrease. However, unlike the previous case, the stabilization provided by the explicit water molecule is insufficient to render the reaction between $\mathrm{AN}$ and $\mathrm{NaNO}_{3}$ competitive with the 
decomposition of pure AN. Therefore, in accordance with experimental results, no incompatibility has been identified between $\mathrm{AN}$ and sodium nitrate, neither in the gas phase nor in the presence of water (or moisture).

\section{Conclusion}

Calorimetry is a useful screening tool for assessing materials in process which are incompatible with AN. Adjusting a parameter, such as humidity, to simulate the industrial environment allows better definition of the conditions which may promote an adverse chemical reaction. However, in part due to the hygroscopic nature of $\mathrm{AN}$ and also to avoid potential damaging effects on costly instrumentation, the degree of experimental control is limited. Instead, results of the theoretical study of the reactions between AN and sodium salts (based only on the rate-determining steps of the reactions) are in qualitative agreement with the calorimetric experiments performed. They confirm the relevance of molecular modeling in the comprehension (and prediction) of chemical incompatibility specific to $\mathrm{AN}$, in complement with experimental analysis. Indeed, theoretical results suggested a different behaviour for the interaction of $\mathrm{AN}$ with $\mathrm{NaNO}_{2}$ and $\mathrm{NaNO}_{3}$ that could imply a different degree of compatibility for these two similar systems $\mathrm{NaNO}_{2} / \mathrm{NaNO}_{3}$. The important role of water in the understanding of AN thermal decomposition in contact with sodium nitrite was also confirmed by both experimental and theoretical approaches. Associated with our previous theoretical studies dedicated to AN thermal decomposition with contaminants, this work confirms the role that $a b$ initio methods could play in the safety management of chemicals in industrial and laboratory contexts in general allowing a better understanding of the subjacent reaction mechanisms.

\section{Acknowledgements}

The authors are grateful to Guy Marlair (INERIS) for useful discussions and Ms. Miao Yao from Nanjing University of Science and Technology for her assistance in performing the DSC measurements.

\section{Supporting Information}

Additional tables as cited in the text. This information is available free of charge via the Internet at http://pubs.acs.org/. 


\section{References}

(1) Mahadevan, E. G. Ammonium Nitrate Explosives for Civil Applications; Wiley: Weinheim, Germany, 2013. Chapter 4 "Ammonium Nitrate and AN/FO".

(2) Bretherick, L. Handbook of Reactive Chemical Hazards; Butterworth: London, UK, 2007.

(3) Gunawan, R.; Freij, S.; Zhang, D.; Beach, F.; Littlefair, M. A mechanistic study into the reactions of ammonium nitrate with pyrite. Chem. Eng. Sci. 2006, 61, 5781.

(4) Oxley, J. C.; Smith, J. L.; Rogers, E.; Yu, M. Ammonium nitrate: thermal stability and explosivity modifiers. Thermochim. Acta 2002, 384, 23.

(5) Sinditskii, V. P.; Egorshev, V. Y.; Levshenkov, A. I.; Serushkin, V. V. Ammonium Nitrate : Combustion Mechanism and the Role of Additives. Propellant, Explos. Pyrotech. 2005, 30, 269.

(6) Keenan, A. G.; Notz, K.; Franco, N. B. Synergistic Catalysis of Ammonium Nitrate Decomposition. J. Am. Chem. Soc. 1968, 22, 3168.

(7) Chaturvedi S.; Dave P. N. Review on Thermal Decomposition of Ammonium Nitrate. J. Energ. Mater., 2013, 31, 1.

(8) Klimova I.; Kaljuvee T.; Türn L.; Bender V.; Trikkel A.; Kuusik R. Interactions of ammonium nitrate with different additives, Thermodynamic analysis. J. Therm. Anal. Cal. 2011, 105, 13.

(9) Han, Z.; Sachdeva, S.; Papadaki, M.I.; Mannan, S. Effects of inhibitor and promoter mixtures on ammonium nitrate fertilizer explosion hazards. Thermochim. Acta. 2016, 624, 69.

(10) United States Environmental Protection Agency, Office of Solid Waste and Emergency Response, EPA 550-F-97-002d December 1997 "Explosion Hazard from Ammonium Nitrate".

(11) Nygaard, E. C. Safety and security of ammonium nitrate, European Federation of Explosive Engineers, Brighton Conference Proceedings, 2005, 27.

(12) Lightfoot P. Hazardous Contaminants of Ammonium Nitrate. SAFEX Newsletter No.36, 1st Qtr. 2011.

(13) Dechy, N.; Bourdeaux, T.; Ayrault, N.; Kordek, M.-A.; Le Coze, J.-C. First lessons of the Toulouse ammonium nitrate disaster, 21st September 2001, AZF plant, France. J. Hazard. Mater. 2004, 111, 131.

(14) Shah, K.D. Ammonium nitrate production, storage and distribution: accidents and investigations (Proc.629), Intl. Fertiliser Soc., York, England, 2008.

(15) Babrauskas, V. Explosions of ammonium nitrate fertilizer in storage or transportation are preventable accidents. J. Hazard. Mater. 2016, 304, 134.

(16) Badeen, C. M.; Kwok, Q. S. M.; Vachon, M. C. R.; Turcotte, R.; Jones, D. E. G. Hazard characterization of mixtures of ammonium nitrate with the sodium salt of dichloroisocyanuric acid. J. Therm. Anal. Cal. 2005, 81, 225.

(17) Li, X.-R.; Koseki, H. Study on reactivity of ammonium nitrate contaminated by sodium dichloroisocyanurate. Sci.Tech. Energetic Materials. 2005, 66, 431. 
(18) Guengant, Y.; Della Pietra, P.; Dervaux, M.; Franson, C.; Jacob, G.; Macé, H. Proceedings of $28^{\text {th }}$ Annual General Meeting of the Federation of European Explosives Manufacturers, Copenhagen, Denmark, 2004, 218.

(19) Cagnina S.; Rotureau P.; Adamo C. Study of Incompatibility of Ammonium Nitrate and its Mechanism of Decomposition by Theoretical Approach. Chemical Engineering Transactions 2013, 31.

(20) Cagnina S.; Rotureau P.; Fayet G.; Adamo C. Modeling Chemical Incompatibility: Ammonium Nitrate and Sodium Salt of Dichloroisocyanuric Acid as a Case Study. Ind. Eng. Chem. Res. 2014, 53, 13920.

(21) Cagnina S. Compréhension des mécanismes d'incompatibilité chimique du nitrate d'ammonium par modélisation moléculaire, UPMC - INERIS, Paris 2014.

(22) Xuguang W. Emulsion Explosives in Metallurgical Industry Press, Beijing 1994.

(23) Yeager K. Hazards of AN formulations employing sodium nitrite and nitrate. Proceedings of the $25^{\text {th }}$ annual conference on explosives and blasting technique Volume 1, 387-395, 1999.

(24) Begg A. H., Hazards in Emulsion Explosives Manufacture and Handling, Understanding what they are and how to avoid them" SAFEX Topical Papers Series Paper No. 05/2008 Published: August 2008.

(25) http://www.factsonline.nl/accident/12709/chemical-accident-in-australia-with-ammoniumnitrate-\%28solid\%29 (accessed June 4, 2015).

(26) Chervin S.; Bodman G. T. Method for estimating decomposition characteristics of energetic chemicals. Process Saf. Prog. 2003, 22, 241.

(27) Cagnina, S.; Rotureau, P.; Fayet, G.; Adamo, C. The ammonium nitrate and its mechanism of decomposition in the gas phase: a theoretical study and a DFT benchmark. Phys. Chem. Chem. Phys. 2013, 15, 10849.

(28) Di Tommaso, S.; Rotureau, P.; Crescenzi, O.; Adamo, C. Oxidation mechanism of diethyl ether: a complex process for a simple molecule. Phys. Chem. Chem. Phys. 2011, 13, 14636.

(29) ASTM E 968-02, Standard Practice for Heat Flow Calibration of Differential Scanning Calorimeters, American Society for Testing and Materials, West Conshohocken, PA. USA.

(30) ASTM E967-03, Standard Practice for Temperature Calibration of Differential Scanning Calorimeters and Differential Thermal Analyzers, American Society for Testing and Materials, West Conshohocken, PA. USA.

(31) Frisch, M.J.; Trucks, G.W.; Schlegel, H.B.; Scuseria, G.E.; Robb, M.A.; Cheeseman, J.R.; Scalmani, G.; Barone, V.; Mennucci, B.; Petersson, G.A.; Nakatsuji, H.; Caricato, M.; Li, X.; Hratchian, H.P.; Izmaylov, A.F.; Bloino, J.; Zheng, G.; Sonnenberg, J.L.; Hada, M.; Ehara, M.; Toyota, K.; Fukuda, R.; Hasegawa, J.; Ishida, M.; Nakajima, T.; Honda, Y.; Kitao, O.; Nakai, H.; Vreven, T.; Montgomery, Jr.J.A.; Peralta, J.E.; Ogliaro, F.; Bearpark, M.; Heyd, J.J.; Brothers, E.; Kudin, K.N.; Staroverov, V.N.; Kobayashi, R.; Normand, J.; Raghavachari, K.; Rendell, A.; 
Burant, J.C.; Iyengar, S.S.; Tomasi, J.; Cossi, M.; Rega, N.; Millam, N.J.; Klene, M.; Knox, J.E.; Cross, J.B.; Bakken, V.; Adamo, C.; Jaramillo, J.; Gomperts, R.; Stratmann, R.E.; Yazyev, O.; Austin, A.J.; Cammi, R.; Pomelli, C.; Ochterski, J.W.; Martin, R.L.; Morokuma, K.; Zakrzewski, V.G.; Voth, G.A.; Salvador, P.; Dannenberg, J.J.; Dapprich, S.; Daniels, A.D.; Farkas, Ö.; Foresman, J.B.; Ortiz, J.V.; Cioslowski, J.; Fox, D.J.; Gaussian 09, rev A.08; Gaussian, Inc.: Wallingford, CT, 2009.

(32) Zhao, Y.; Truhlar, D. G. A new local density functional for main-group thermochemistry, transition metal bonding, thermochemical kinetics, and noncovalent interactions. J. Chem. Phys. 2006, 125, 194101.

(33) Krishnan, R.; Binkley, J.S.; Seeger, R.; Pople, J.A. Self-consistent molecular orbital methods. XX. A basis set for correlated wave functions. J. Chem. Phys. 1980, 72, 650.

(34) McLean, A.D.; Chandler, G.S. Contracted Gaussian basis sets for molecular calculations. I. Second row atoms, Z=11-18. J. Chem. Phys. 1980, 72, 5639.

(35) Gonzalez, C.; Schlegel, H.B. An improved algorithm for reaction path following. J. Chem. Phys. 1989, 90, 2154.

(36) Tomasi, J.; Mennucci, B.; Cammi R. Quantum mechanical continuum solvation models. Chem. Rev. 2005, 105, 2999.

(37) $\mathrm{MSDS} \mathrm{NaNO}_{2}$ and $\mathrm{NaNO}_{3}$

$\mathrm{NaNO}_{2}: \quad$ http://www.avantormaterials.com/documents/MSDS/usa/sap/00028195.pdf (accessed March 1, 2016).

$\mathrm{NaNO}_{3}: \quad$ http://www.avantormaterials.com/documents/MSDS/usa/sap/00027790.pdf (accessed March 1, 2016).

(38) Shah K. D., Roberts A. G. Properties of Ammonium Nitrate in Fertilizer Science and Technology Series Vol. 4; "Nitric Acid and Fertilizer Nitrates" Ed. C. Keleti, Marcel Dekker Inc. New York, 1985.

(39) Addison C.C., Sutton D. Complexes Containing the Nitrate Ion in Progress in Inorganic Chemistry, Vol. 8, (Ed F.A. Cotton), Wiley: Hoboken, NJ, USA, 1967.

(40) Stern K.H. High Temperature Properties and Decomposition of Inorganic Salts Part 3, Nitrates and Nitrites. J. Phys. Chem. Ref. Data, 1972, 1, 747.

(41) International Plant Nutrition Institute - Nutrient Source Specifics: $\mathrm{NaNO}_{3}$ http://www.ipni.net/publication/nss.nsf/0/559A41F30743EACB85257B20007AAEDF/\$FILE/NSS -24\%20SN.pdf (accessed March 1, 2016).

(42) Agrawal J. P. High Energy Materials: Propellants, Explosives and Pyrotechnics, Wiley: Great Britain, 2010.

(43) European fertilizer manufacturers association, "Guidance for the compatibility of fertilizer blending materials", Brussels, Belgium, 2006. 
(44) Freeman E.S. The Kinetics of the Thermal Decomposition of Sodium Nitrate and of the Reaction between Sodium Nitrite and Oxygen. J. Phys. Chem., 1956, 60, 1487.

(45) Bond B.D.; Jacob P.W.M. Thermal Decomposition of Sodium Nitrate. J. Chem. Soc. (A), 1966, 1265. 
Table 1. Enthalpy of decomposition for the first exotherm detected by DSC and HFC in Figure 1

\begin{tabular}{|c|c|c|c|c|c|c|}
\hline & \multicolumn{3}{|c|}{$\begin{array}{l}\text { Decomposition Onset } \\
\text { Temperature } /{ }^{\circ} \mathrm{C}\end{array}$} & \multicolumn{3}{|c|}{ Enthalpy / kJ g ${ }^{-1}\left(\mathrm{kcal} \mathrm{mol}^{-1}\right)^{*}$} \\
\hline & Dry & Humid & $\begin{array}{c}\text { Excess } \\
\text { water }\end{array}$ & Dry & Humid & $\begin{array}{l}\text { Excess } \\
\text { water }\end{array}$ \\
\hline (DSC) AN & 220 & -- & -- & $0.47(8.6)$ & -- & -- \\
\hline (DSC) $\mathrm{AN}+\mathrm{NaNO}_{2}$ & 55 & 55 & 55 & $1.34(23.8)$ & $1.36(21.8)$ & $1.35(21.7)$ \\
\hline (DSC) $\mathrm{AN}+\mathrm{NaNO}_{3}$ & 218 & 185 & 182 & $0.08 * *(1.6)$ & $0.25(4.6)$ & $0.35(5.7)$ \\
\hline (HFC) $\mathrm{AN}+\mathrm{NaNO}_{2}$ & 54 & & & $1.77(29.6)$ & & \\
\hline
\end{tabular}

* The conventional enthalpy (integrated area, $\mathrm{kJ} \mathrm{g}^{-1}$ ) obtained using calorimeter analysis software, and conversion to $\mathrm{kcal} \mathrm{mol}^{-1}$ calculated using total moles of all starting materials.

$* * \Delta \mathrm{H}$ of partial exotherm before DSC pan rupture 
Table 2. Relative energies $\left(\mathrm{kcal} \mathrm{mol}^{-1}\right)$ of the reactions between $\mathrm{AN}$ and sodium salts in gas phase

\begin{tabular}{|c|c|c|c|}
\hline & $\Delta \mathbf{E}$ & $\Delta \mathbf{H}$ & $\Delta \mathbf{G}$ \\
\hline \multicolumn{4}{|c|}{$\underline{\mathrm{AN}}+\mathrm{NaNO}_{2}$ reaction } \\
\hline $\mathrm{NH}_{4} \mathrm{NO}_{3}$ & 0.0 & 0.0 & 0.0 \\
\hline $\mathrm{NH}_{3}+\mathrm{HNO}_{3}$ & 15.3 & 14.0 & 4.9 \\
\hline $\mathrm{TS}_{\mathrm{NaNO} 2+\mathrm{HNO} 3}$ & 50.0 & 47.4 & 49.0 \\
\hline $\mathrm{NaOH}+2 \mathrm{NO}_{2}$ & 49.5 & 47.7 & 45.6 \\
\hline \multicolumn{4}{|c|}{$\underline{\mathrm{AN}}+\mathrm{NaNO}_{3}$ reaction } \\
\hline $\mathrm{NH}_{4} \mathrm{NO}_{3}$ & 0.0 & 0.0 & 0.0 \\
\hline $\mathrm{NH}_{3}+\mathrm{HNO}_{3}$ & 15.3 & 14.0 & 4.9 \\
\hline $\mathrm{TS}_{\mathrm{NaNO}+\mathrm{HNO}}$ & 57.9 & 55.4 & 55.6 \\
\hline $\mathrm{NaOH}+\mathrm{N}_{2} \mathrm{O}_{5}$ & 40.8 & 38.8 & 45.8 \\
\hline
\end{tabular}




\section{Figure captions}

Figure 1. Thermograms of $\mathrm{NaNO}_{2}, \mathrm{NaNO}_{3}$ and their mixtures with ammonium nitrate.

Figure 2. Geometry of the transition state of the reaction between sodium nitrite and ammonium nitrate in gas phase, with water molecule, with the PCM approach on $\mathrm{AN}-\mathrm{NaNO}_{2}$ dimer and with the PCM approach on $\mathrm{AN}-\mathrm{NaNO}_{2}-\mathrm{H}_{2} \mathrm{O}$ trimer.

Figure 3. Comparison of M06-2X/6-311+G(2d,2p) Gibbs energy profiles $\left(\mathrm{kcalmol}^{-1}\right)$ for the reaction between $\mathrm{AN}$ and $\mathrm{NaNO}_{2}$ in gas phase (black), with one explicit water molecule (blue), with PCM (red) and with the discrete-continuum model (green) (PCM + one explicit water molecule).

Figure 4. Relation between the sodium charge and the activation energy for the reaction AN $+\mathrm{NaNO}_{2}$ and $\mathrm{AN}+\mathrm{NaNO}_{3}$ with a water molecule.

Figure 5. Geometry of the transition state of the reaction between sodium nitrate and ammonium nitrate in gas phase, with a water molecule, with the PCM approach on AN$\mathrm{NaNO}_{3}$ dimer and with the PCM approach on $\mathrm{AN}-\mathrm{NaNO}_{3}-\mathrm{H}_{2} \mathrm{O}$ trimer.

Figure 6. Comparison of M06-2X/6-311+G(2d,2p) Gibbs energy profiles (kcal/mol) for the reaction between $\mathrm{AN}$ and $\mathrm{NaNO}_{3}$ in gas phase (black), with one explicit water molecule (blue), with PCM (red) and with the discrete-continuum model (green) $(\mathrm{PCM}+$ one explicit water molecule). 

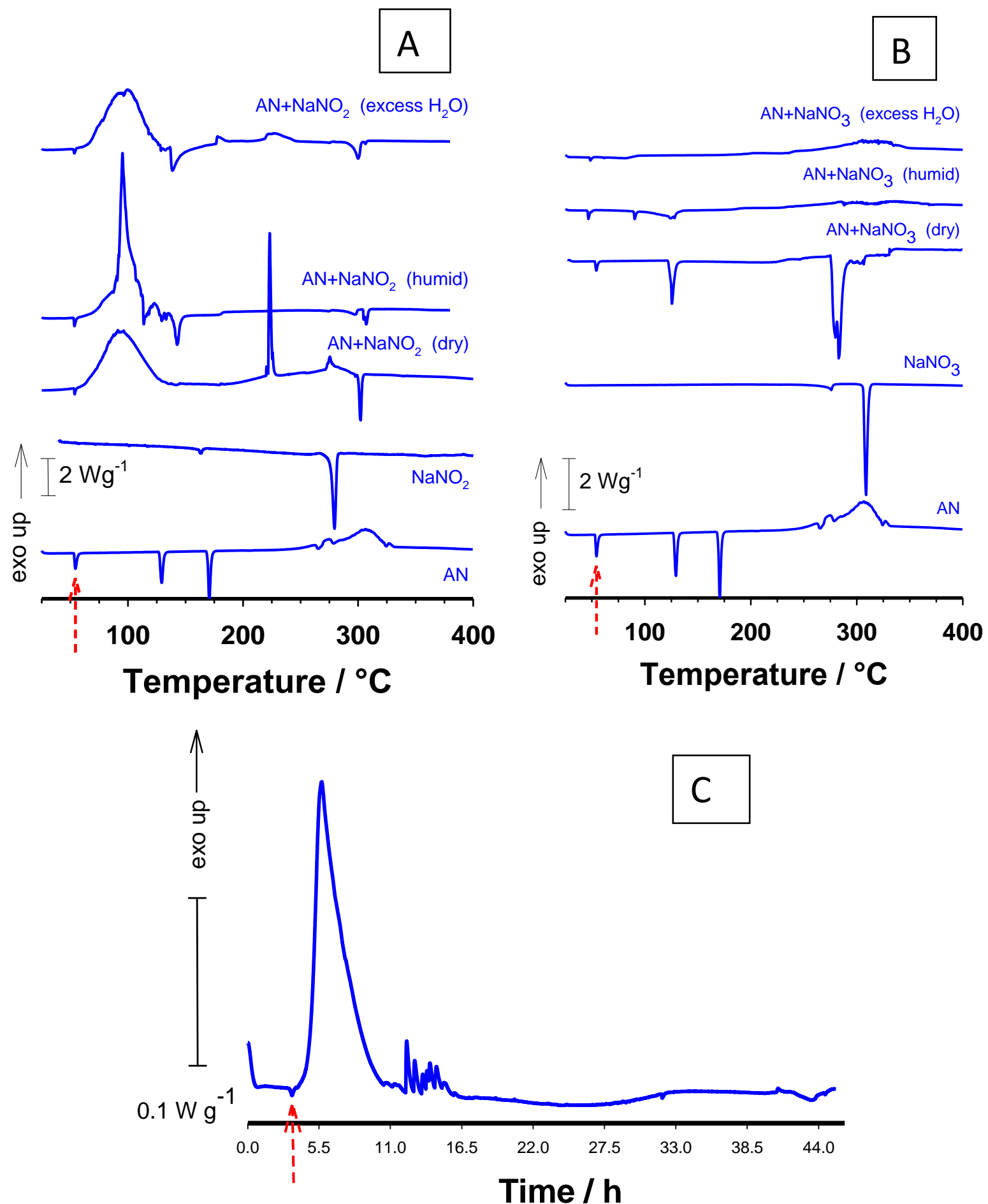

Figure 1. Thermograms of $\mathrm{NaNO}_{2}, \mathrm{NaNO}_{3}$ and their mixtures with ammonium nitrate.

A) DSC of $\left[\mathrm{AN}+\mathrm{NaNO}_{2}\right]$, B) DSC of $\left[\mathrm{AN}+\mathrm{NaNO}_{3}\right]$ and C) $\mathrm{HFC}$ of $\left[\mathrm{AN}+\mathrm{NaNO}_{2}\right]$. For DSC thermograms the data has been transposed on the y-axis for clarity. The position of the endothermic $\mathrm{AN}$ solid-solid phase transition at $55^{\circ} \mathrm{C}$ is indicated by a red arrow on the $\mathrm{x}$-axis for each system. 


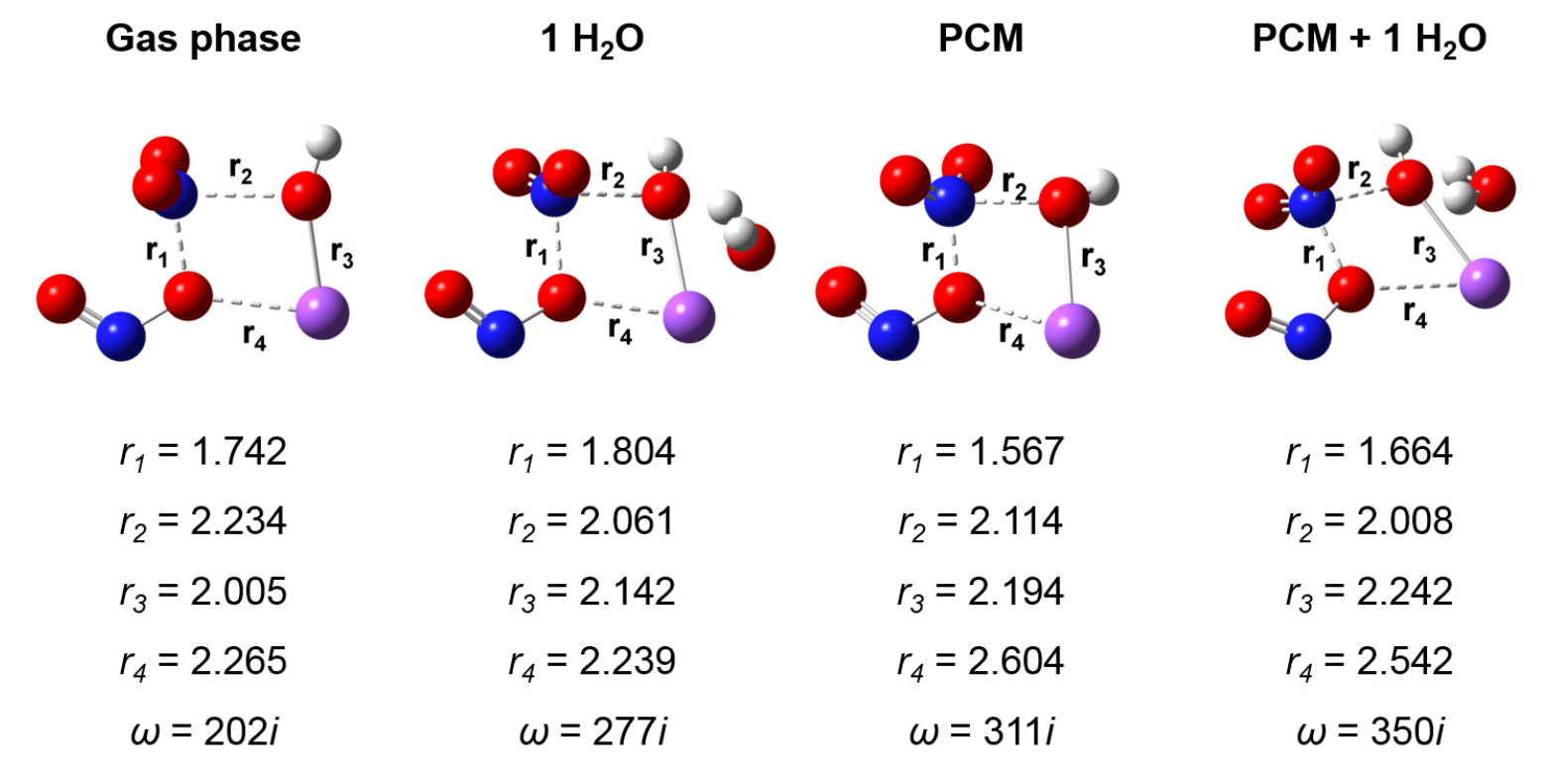

Figure 2. Geometry of the transition state of the reaction between sodium nitrite and ammonium nitrate in gas phase, with water molecule, with the PCM approach on $\mathrm{AN}-\mathrm{NaNO}_{2}$ dimer and with the PCM approach on $\mathrm{AN}-\mathrm{NaNO}_{2}-\mathrm{H}_{2} \mathrm{O}$ trimer. 


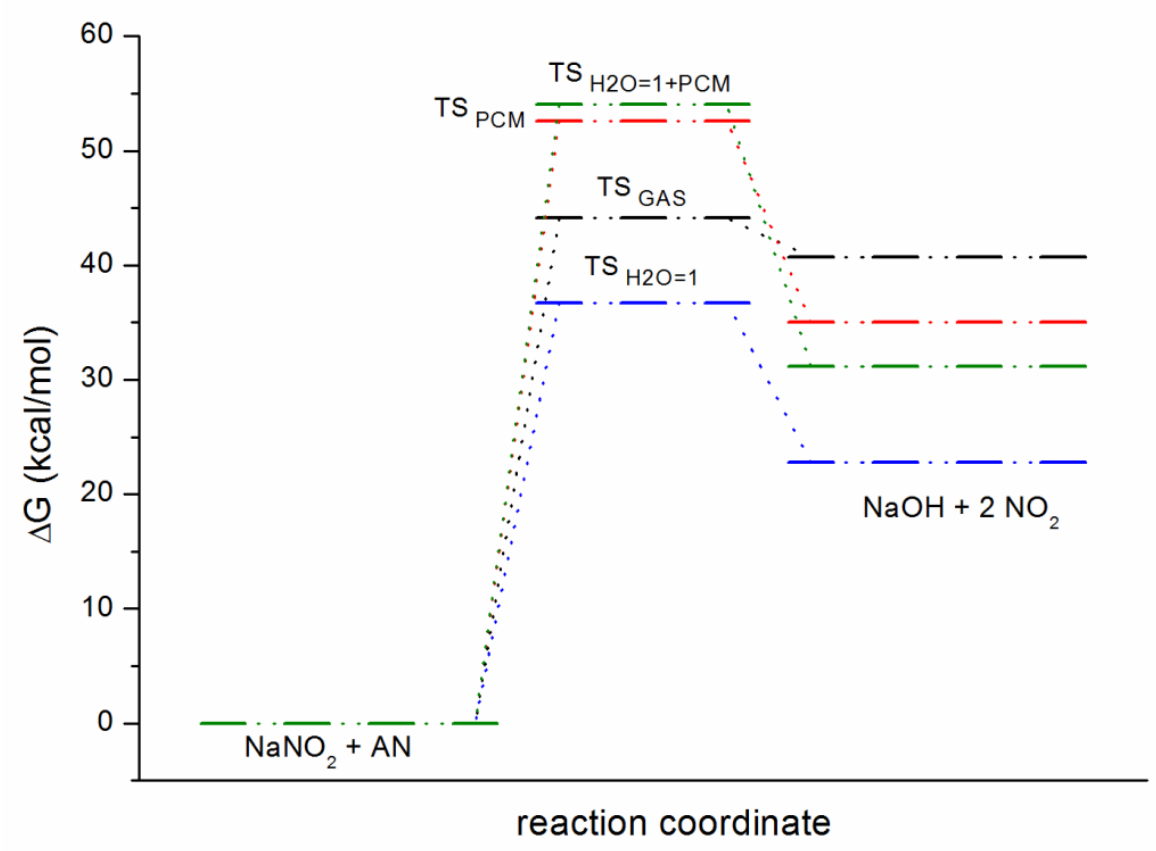

Figure 3. Comparison of M06-2X/6-311+G(2d,2p) Gibbs energy profiles (kcal/mol) for the reaction between $\mathrm{AN}$ and $\mathrm{NaNO}_{2}$ in gas phase (black), with one explicit water molecule (blue), with $\mathrm{PCM}$ on $\mathrm{AN}-\mathrm{NaNO}_{2}$ (red) and with $\mathrm{PCM}$ on $\mathrm{AN}-\mathrm{NaNO}_{2}-\mathrm{H}_{2} \mathrm{O}$ trimer (green). 

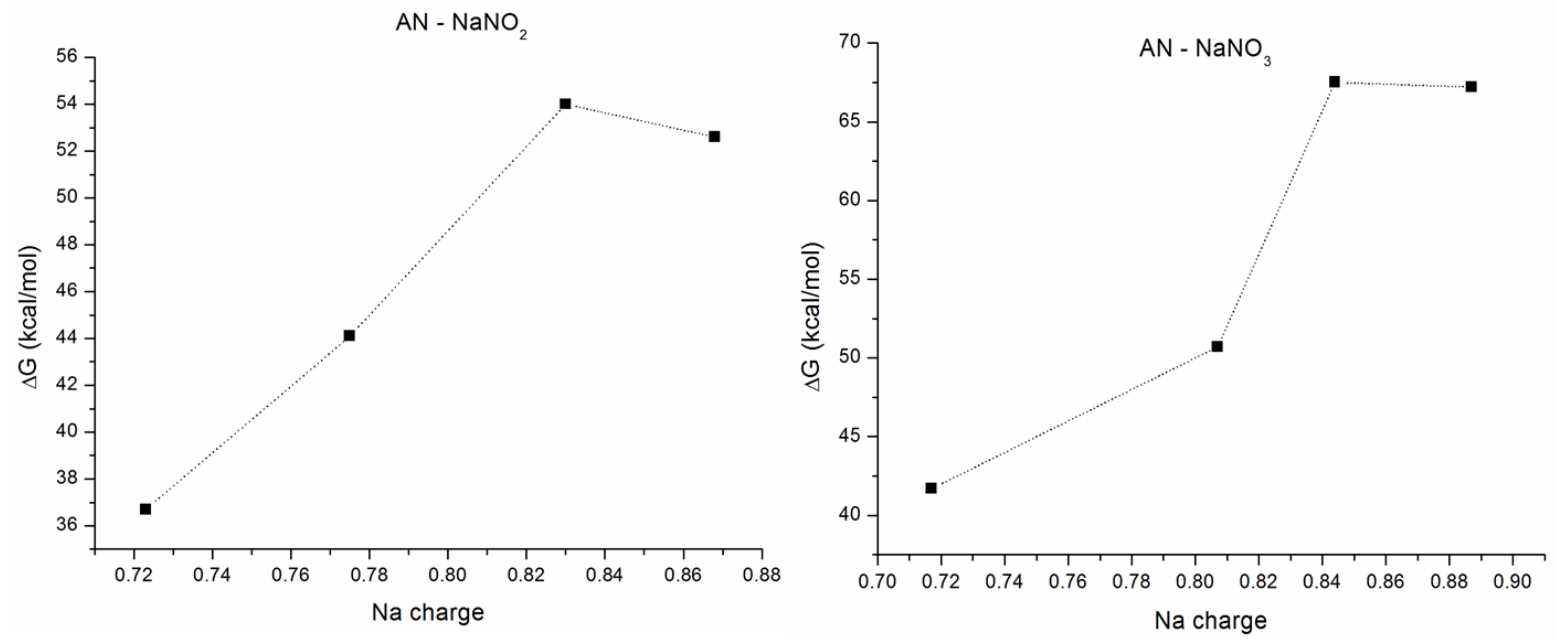

Figure 4. Relation between the Mulliken sodium charge and the activation energy for the reaction $\mathrm{AN}+\mathrm{NaNO}_{2}$ and $\mathrm{AN}+\mathrm{NaNO}_{3}$ with a water molecule. 


$\begin{array}{cccc}\text { Gas phase } & & \\ r_{1}=1.741 & r_{1}=1.782 & r_{1}=1.573 & r_{1}=1.722 \\ r_{2}=2.235 & r_{2}=2.314 & r_{2}=2.216 & r_{2}=2.175 \\ r_{3}=2.007 & r_{3}=2.172 & r_{3}=2.183 & r_{3}=2.239 \\ r_{4}=2.267 & r_{4}=2.246 & r_{4}=2.980 & r_{4}=2.547 \\ \omega=256 i & \omega=212 i & \omega=271 i & \omega=366 i\end{array}$

Figure 5. Geometry of the transition state of the reaction between sodium nitrate and ammonium nitrate in gas phase, with a water molecule, with the PCM approach on AN$\mathrm{NaNO}_{3}$ dimer and with the PCM approach on $\mathrm{AN}-\mathrm{NaNO}_{3}-\mathrm{H}_{2} \mathrm{O}$ trimer. 


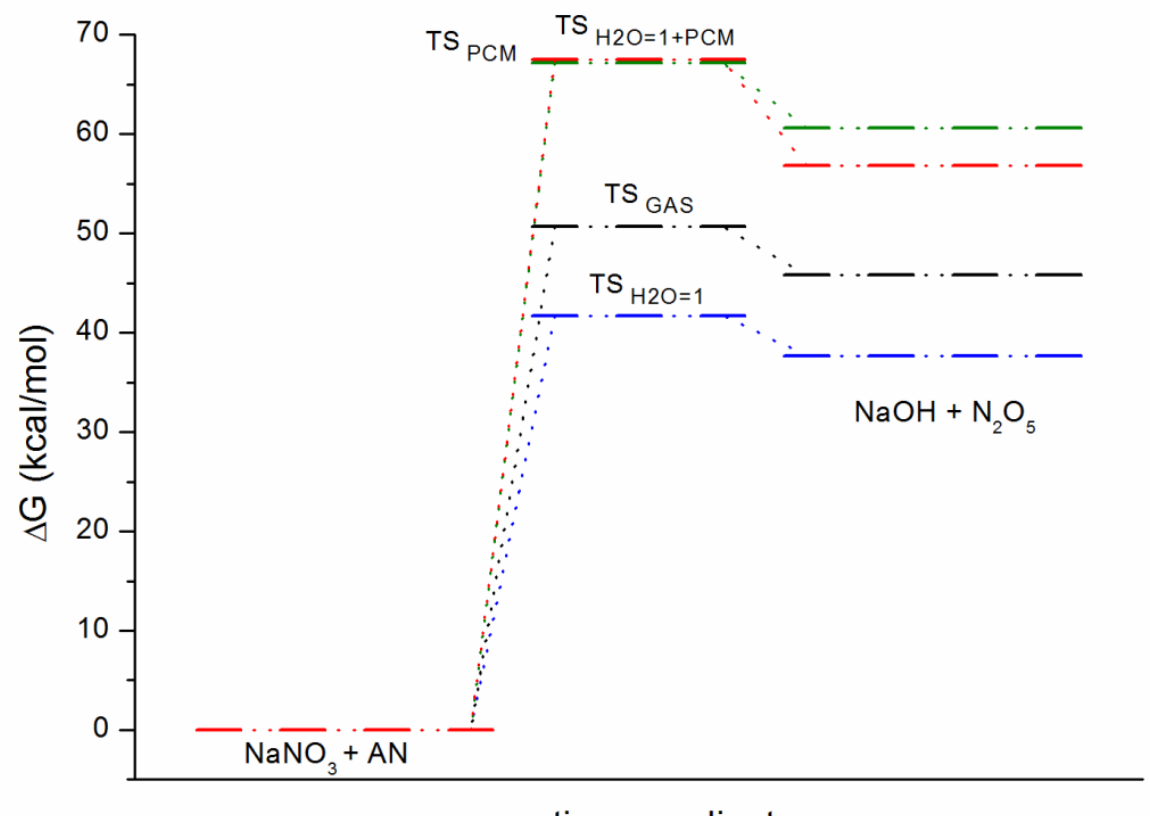

reaction coordinate

Figure 6. Comparison of M06-2X/6-311+G(2d,2p) Gibbs energy profiles ( $\mathrm{kcal} / \mathrm{mol})$ for the reaction between $\mathrm{AN}$ and $\mathrm{NaNO}_{3}$ in gas phase (black), with one explicit water molecule (blue), with $\mathrm{PCM}$ on $\mathrm{AN}-\mathrm{NaNO}_{3}$ dimer (red) and with $\mathrm{PCM}$ on $\mathrm{AN}-\mathrm{NaNO}_{3}-\mathrm{H}_{2} \mathrm{O}$ trimer. 
Table of Contents

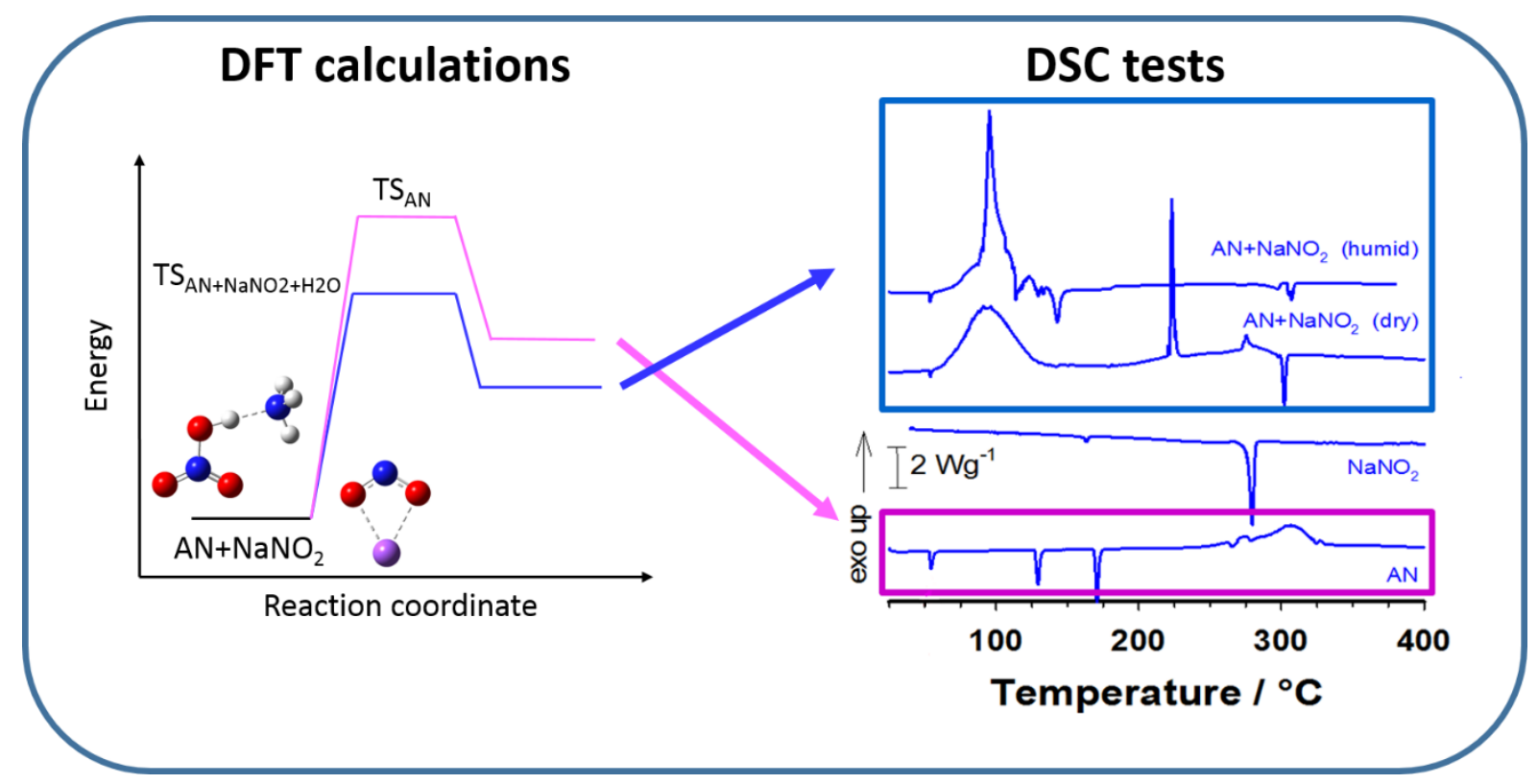

